\title{
EL UNIVERSO FEMENINO EN LAS NOVELAS DE CHIQUITA BARRETO
}

\author{
KRYSTYNA PISERA
}

Universidad del Norte, Paraguay

\begin{abstract}
Resumen. El universo femenino en las novelas de Chiquita Barreto. La literatura paraguaya, salvo algunas excepciones, es muy poco conocida. Esta falta de conocimiento se manifiesta tanto en los lectores como en la crítica literaria. Dentro del corpus literario paraguayo, la literatura femenina ocupa un lugar importante. Chiquita Barreto, escritora, maestra y feminista paraguaya es autora de novelas como: Mujeres de cera (2010), La voz negada (2011), Al amparo del tiempo (2012), Los nombres que habito (2015), ¿Dónde van los gatos cuando llueve? (2012), y otras colecciones de cuentos y poemas. En sus escritos, Barreto siempre aborda los problemas de las mujeres. Este artículo presenta un análisis de sus novelas, verificando su lugar dentro de los temas principales de la literatura femenina latinoamericana, especialmente los del post-boom. Este es un espacio narrativo donde se alteran los códigos y se reinterpretan los conceptos. Por lo tanto, la inclusión del cuerpo femenino como libre e independiente da como resultado una literatura erótica libre de inhibiciones. Por otro lado, este cuerpo se convierte en una condena de la violencia de género. La legitimación y revalorización de los espacios domésticos marginados como la cocina, produce lo que llamamos gastrotextos. La participación femenina en la lucha contra las dictaduras se recupera para la memoria colectiva. Dentro del contexto paraguayo, el tema de la militancia femenina en la resistencia contra la dictadura había venido siendo marginado. El rescate de mujeres víctimas de la dictadura tiene una importancia fundamental en la narrativa de Barreto. A través de la voz de sus heroínas, la autora relata los conflictos familiares y políticos, combinando historias íntimas con la historia de Paraguay, llena de violencia y dolor.
\end{abstract}

Palabras clave: literatura paraguaya, Chiquita Barreto, feminismo, dictadura

\section{INTRODUCCIÓN}

La literatura paraguaya, salvo algunas - escasas - excepciones es poco conocida. Posiblemente, el origen de este desconocimiento se encuentre en el hecho de que la narrativa paraguaya surge tardíamente en comparación con la de otros países latinoamericanos. (Este atraso se debe a factores históricos, sociales y políticos). Las primeras novelas editadas en Paraguay, en la primera década del s. XX, son de autores extranjeros y hubo que pasar tiempo hasta los años 50 para que aparezcan obras de narradores paraguayos de dimensión continental: Gabriel 
Casaccia (1907-1980), José María Rivarola Mato (1917-1998), Augusto Roa Bastos (1917-2001), Rubén Bareiro Saguier (1930-2014), Carlos Villagra Marsal (1932-2016) y otros autores (Méndez-Faith, 2009: 43). Entre ellos suenan apenas tres nombres femeninos: Teresa Lamas, Josefina Plá y Concepción Leyes. De manera que, la narrativa paraguaya se afianza como género literario ya en pleno s.XX.

La misma situación de atraso se repite en caso de la literatura escrita por mujeres. En otros países latinoamericanos las escritoras del post boom tuvieron sus antecesoras ya en el s. XIX. En Brasil, (Dionisia Gonçalves Pinto (1810-1885), María Finnina des Reis (1825-1917), Perú, (Mercedes Cabello de Carbonara (1842-1909), Clorinda Matto de Turner (1852-1909), más tarde, en Chile, Gabriela Mistral (1889-1957), en Argentina, Alfonsina Storni (1892-1979) y Juana Ibarbourou (1892-1979) en Uruguay. Ellas han trazado camino para las siguientes, que han irrumpido en el paisaje literario internacional: las mexicanas Elena Poniatowska (1932-), Angeles Mastretta, (1949-), Laura Esquivel (1950-), las chilenas Isabel Allende (1942-) y Marcela Serrano (1951-), Gioconda Belli, nicaragüense (1948-), Laura Restrepo, colombiana (1950-), las puertorriqueñas Rosario Ferré (1938-) y Ana Lydia Vega, (1946-), para nombrar algunas.

En Paraguay, esta abundancia de mujeres escritoras ocurrió con retardo (que se explica desde lo histórico, social y cultural), ya bien entrados los años 80 del s. XX cuando 'el elenco cultural femenino es potencialmente más numeroso de lo que se piensa en principio, y en los años noventa incluso más extenso que el masculino' (Peiró Barco y Rodríguez Alcalá, 2000: 4).

Reneé Ferrer, Raquel Saguier († 2007), Yula Riquelme, Lita Pérez Cáceres, Maybell Lebron, María Eugenia Garay, Maribel Barreto, Lourdes Talavera, Susana Gertopan, Chiquita Barreto, Luz Saldívar, Estela Franco, son nombres de autoras que ocupan un segmento cada vez más importante del corpus narrativo paraguayo. La lista, obviamente, no está completa.

El objetivo del presente trabajo es analizar la obra de Chiquita Barreto (nombre artístico de Amelia Barreto Burgos), escritora paraguaya, docente, feminista, autora de novelas, cuentos y poemarios e identificar las características que permiten ubicarla dentro de lo que se llama literatura femenina latinoamericana del post boom, lugar que le corresponde desde el punto de vista generacional, temático y estilístico. Como es un artículo de reflexión - descriptivo y explicativo, no precisa de un apartado metodológico específico. Primero se describirán los principales ejes de la literatura femenina latinoamericana del post boom para luego señalar cómo se manifiestan en las novelas de Barreto. Se emplea el término literatura femenina, según como lo usa Adelaida Martínez en su ensayo Feminismo y literatura en Latinoamérica al referirse a la narrativa escrita por mujeres que:

[...] rompe con el status quo y crea universos que corresponden a sus propios valores, sin negar su biología y desde su perspectiva de mujer. El resultado es un nuevo canon en la literatura: una imagen 
de la realidad captada con ojos de mujer y plasmada con discurso hémbrico. Imagen que [...] ahora se configura en una abundantísima publicación de textos, los que han llegado a constituir un corpus con su propio contexto, su propia voz y su propia visión, la cual debe ser juzgada por sus propios méritos. (Martínez, 2002: 1)

\section{DESARROLLO}

Martínez considera como un rasgo definitorio fundamental de la literatura femenina latinoamericana su 'diversa y multidimensional especificidad cultural, repartida en diecinueve países' (Martínez, 2002: 2). Las vivencias femeninas en los países que presentan profundas diferencias en su constitución racial, en su desarrollo histórico y en sus estructuras sociopolíticas serán también diferentes, hasta incomparables en muchos casos.

Con todo, hay elementos unificadores que abarcan lo temático, estructural y discursivo. En primer lugar, la incorporación de la problemática del colonialismo. La cuestión del colonialismo fundacional español presenta un abordaje difícil desde el enfoque machista y patriarcal. En el caso del Paraguay funciona el mito - uno de los mitos nacionalistas - de la supuesta entrega amorosa de las mujeres guaraníes a los conquistadores españoles, dando así el inicio al proceso de mestizaje y subsiguiente fundación de la sociedad paraguaya (Makaran, 2014). En caso de México, en cambio, se impone la visión del vencido y se incorpora la chingada al imaginario colectivo, de lo que habla Octavio Paz en El laberinto de la Soledad:

¿Quién es la Chingada? Ante todo, es la madre. No una madre de carne y hueso, sino una figura mítica. La Chingada es una de las representaciones mexicanas de la Maternidad [...] es la madre que ha sufrido, metafórica o realmente, la acción corrosiva e infamante implícita en el verbo que le da nombre. (Paz, 1950: 68)

Esta visión, desde la óptica del vencido, se enlaza con otro tema ausente en otras lenguas europeas: la relación telúrica de la mujer con el planeta.

El cuerpo violado de la mujer indígena desde la conquista [...] se ha convertido en la imagen arquetípica de la madre tierra cuyo cuerpo [...] es continuamente asaltado por los buscadores de oro de todos los tiempos. (Martínez, 2002: 4)

Esta manera de concebir a la imagen de la madre hace que el mito de la maternidad en Latinoamérica adquiere dimensiones diferentes. Va más allá de la función biológica de la reproducción. En el s.XX 'las madres latinoamericanas inscriben sus cuerpos como signos en el texto de la historia para denunciar los horrores de las dictaduras', como lo hicieron Las Madres de la Plaza de Mayo, en Argentina, que se han convertido en un símbolo de resistencia y denuncia (ibid., 2002). El tema de las dictaduras es recurrente en la narrativa femenina del post 
boom. Las escritoras incluyen los elementos silenciados por la historia oficial, omitidos en el discurso patriarcal, en el que la figura de la mujer-víctima de la dictadura es invisibilizada. En contraposición a la historia oficial escriben las historias personales propias o ajenas, haciendo uso de variados recursos formales; testimonio, crónica, memorias o parodia. Usan lo privado para subvertir lo público.

Subversión deviene también en legitimación y revalorización de los espacios marginados domésticos, como la cocina. Los espacios considerados como limitantes y secundarios se convierten en lugares de superación y empoderamiento. Los gastrotextos, como los llama Martínez (2002), de Laura Esquivel, Rosario Castellanos o Amparo Dávila destacan además en la calidad del lenguaje literario, sensual, voluptuoso, imaginativo y con poder metafórico que va más allá de lo culinario.

La audacia en escribir sobre el cuerpo femenino y la sexualidad, como también el humor, son características que deben ser agregados a estas consideraciones generales concernientes a la literatura femenina del post boom.

Dentro de este marco situamos la obra de Chiquita Barreto, específicamente sus novelas: Mujeres de cera (2009), La voz negada (2011), Al amparo del tiempo (2012), Los nombres que habito (2015) ¿Dónde van los gatos cuando llueve? (2017).

En la introducción a Mujeres de cera Graciela González Meyer dice:

Chiquita Barreto, al narrar y reflexionar utiliza el lenguaje y la terminología femenina porque da cuenta del confinamiento de las mujeres, de qué manera ellas responden a los estereotipos creados para sostener el orden patriarcal donde hasta ahora la violencia de género [...] está naturalizada y es percibida todavía [...] como el lugar predestinado. (Barreto, 2010: 22)

Son historias de vida de cinco mujeres que, de adolescentes, estaban enamoradas del mismo joven. Para ayudarle a elegir a una de ellas, organizan una especie de bacanales. Para la ocasión, ellas -las sacerdotisas organizadoraselaboran un licor al que llaman mistela.

La novela tiene dos hilos conductores que se entrelazan, sobreponen, y discurren en paralelo o a veces entran en diálogo. Uno, conformado por las historias privadas, cotidianas, íntimas y, otro, crónicas de movimientos guerrilleros, de las Ligas Agrarias, de persecuciones en los años 60 y 70 en Paraguay. Asimismo, la autora recurre a dos lenguajes diferentes. Uno, que nos pinta la vida cotidiana de mujeres sometidas al control patriarcal que les impone el matrimonio como una obligación y que, sin embargo, encuentran maneras de ejercer la libertad prohibida, de abrirse a sus deseos sexuales, transgredir las reglas, disfrutar. Y otro, un lenguaje de crónicas, de relato histórico que se impone con su contenido cruel. La escritora recurre al primero para otorgar un sentido a la vida cotidiana y sus espacios. La cocina y el hogar tienen la función de 'consolidar 
y preservar todo lo que nutre, alumbra y calienta la existencia, en contra de todo aquello que la debilita, la ennegrece o la congela'. La cocina y el fuego devienen el principio que enciende la vida, y la mujer en el hogar es la protectora (López González en Zawierzeniec, 2015: 147).

El lenguaje de la cocina se mezcla con el lenguaje amoroso. Los dos involucran sentidos: gustativo, olfativo, del tacto y otros. No debe sorprendernos que a veces se hable de la pasión amorosa de igual manera que del apetito.

La vida parece eterna.

Se eterniza en la piel que palpita.

Se eterniza en la tibia humedad que gotea lentamente en el centro de la gravedad de sus cuerpos apasionados y fogosos.

Una montaña dorada de mandarina.

El balde lleno de jugo amarillo, impregnando con el ácido aroma la humilde cocina.

El licor inventado.

Hierve el jugo. Se convierte en ámbar líquido.

Está haciéndose la mistela. El licor inventado para navegar el río que galopa en la sangre.

El jugo de mandarina hirviendo con azúcar, canela y pimienta y mezclado después con alcohol puro. (Barreto, 2015: 23)

Todos mis sentidos se movilizan: con ellos veo, oigo y huelo el pasado; saboreo lo dulce y se me atora en la garganta lo amargo. (ibid.: 31 )

Lo social y lo político que determina las historias personales de las protagonistas, las posturas que cada una de ellas asume frente a las circunstancias que, básicamente, son limitantes, constituyen un marco para el universo femenino en esta novela y las siguientes.

Al amparo del tiempo abarca un período largo, permitiendo observar el derrotero que transitan las protagonistas desde una cierta perspectiva temporal. Es una narración al estilo de una saga familiar que transcurre desde el año 1922, cuando en Paraguay se produce una guerra civil, hasta los tiempos del fin de la dictadura de Stroessner (1989). Una bebita abandonada en la calle es recogida por una monja cocinera. Recibe el nombre de María Pía y crece dentro de la cocina aprendiendo los conocimientos culinarios transmitidos por la madre adoptiva, hasta que llega a la edad cuando conviene destinarle una pieza para ella sola. Allí, en la oscuridad de la noche, la visita un hombre. Embarazada, María Pía tiene que abandonar el convento y, para sobrevivir, abre un modesto comedor que con el tiempo se convertirá en el restaurante más prestigioso del país, mencionado en las guías turísticas internacionales.

María Pía tuvo cuatro hijas con el hombre misterioso (que resultó ser un obispo), todas Marías: María Victoria, María Laura, María Candela, María Eugenia. Cada una de ellas tiene su manera de encarar la vida, de vivir sus amores, de enfrentar las limitaciones sociales, culturales o incluso familiares. Sus 
historias íntimas se entremezclan con la historia del país. Ante nuestros ojos se despliega un amplio panorama que permite observar cómo, con el tiempo, las mujeres consiguen liberarse de las ataduras y ser artífices de sus propios destinos.

Como muchas mujeres paraguayas, María Pía tiene que encargarse de sus hijas ella sola y lo consigue. La historia del imperio gastronómico fundado por ella podría parecer una fábula perteneciente al realismo mágico, si no fuera por el hecho de que se conocen historias así en la vida real, siendo parte de lo real maravilloso, que se ajusta perfectamente al concepto desarrollado por Alejo Carpentier.

Los nombres que habito trae más historias de mujeres, crónicas de represión, a menudo ejercida por personas más cercanas, como el padre, que en vez de ser una figura protectora es un represor desalmado. Igual es el caso del abuelo en Las mujeres de cera. La nieta, a pesar de su rebeldía y personalidad, se subordina a su voluntad y acepta un matrimonio con un viejo rico. El matrimonio dura 20 años. Solo cuando enviuda, Catalina enfrenta a la sociedad y se entrega al verdadero amor. Habla al marido ya muerto:

Verme forzada al matrimonio contigo me hizo descubrir que el mundo le pertenece a los hombres; las mujeres estamos solo para hacerles la vida más cómoda y para obedecer. Vos Azuel, eras más viejo que mi abuela y ninguna mujer con esta edad se atrevería a ofrecer matrimonio a un muchacho sin exponerse a la condena moral y a las burlas, en el mejor de los casos, y hasta a ser linchada en una plaza.

Y sin embargo vos conseguiste que mi abuelo se sintiera orgulloso de entregarme para ser tu esposa. (ibid.: 82)

En esta obra, como en las anteriores, se mezclan historias personales e historia general del país, resaltando el tema de en las niñas raptadas para ser esclavas sexuales del dictador Stroessner y sus generales amigos.

Donde van los gatos cuando llueve, es la última novela de Chiquita. 'Los recuerdos son como los gatos en los días de lluvia. Están escondidos en algún sitio. Aparecen no se sabe de dónde.' (Barreto, 2017: 9). Vienen y van cuando quieren, provocan una sonrisa o hunden en tristeza. Serán recuerdos compartidos con algunos lectores, para otros serán historias alegres o dolorosas. Algunas de estas historias siguen ocurriendo. El dictador se fue, pero quedan sus herederos. La herencia intangible, la que se afincó en las cabezas de la gente, es la más difícil para desterrar.

Las mujeres de las novelas de Barreto se entregan al amor y se entregan a las luchas porque tienen derecho, porque quieren. Son mujeres osadas. Chiquita Barreto tiene también esa osadía, no solamente como persona solidaria con los movimientos feministas y comprometida con los movimientos sociales en general, sino también como escritora que se alía con las nuevas vertientes presentes en la narrativa femenina latinoamericana del post boom. En sus novelas 
detectamos perfectamente las características fundamentales atribuidas a la narrativa femenina de esta corriente.

La resignificación de lo doméstico, especialmente la cocina, magistralmente lograda por Laura Esquivel al más puro estilo del realismo mágico, Chiquita Barreto lo vuelve maravillosamente real, inspirada por casos verdaderos de mujeres paraguayas. Así mismo, resignifica la simbología de la cocina y el fuego como elemento que alumbra, calienta, protege y fortalece.

La sexualidad y el cuerpo femenino, el erotismo, el derecho al placer son temas que la autora incorpora a sus escritos, enfocados desde el punto de vista de la mujer y expresados con un lenguaje atrevido y directo. Habla del despertar sexual (Mujeres de cera), de la potestad de mujer sobre su cuerpo y del goce que le puede dar. Con crudeza habla del cuerpo de una trabajadora sexual expuesto a la voluntad de los clientes (Donde van los gatos cuando llueve). Usa un lenguaje violento y chocante al relatar los abusos, las violaciones, las mutilaciones de este cuerpo femenino en las mazmorras del dictador.

Barreto denuncia la opresión del sistema patriarcal impuesto como modelo único, según el cual la mujer solo se puede realizar en el papel de esposa y madre y está totalmente subordinada al varón - esposo, padre, hermano o abuelo. El caso extremo de opresión y rebeldía es el de Érica en Dónde van los gatos cuando llueve. El padre no acepta la desobediencia de la hija y, al querer doblegarla, provoca una situación que la lleva a trabajar como prostituta en el extranjero. Él, en represalia, la declara muerta y le hacerle llegar el certificado de defunción. Nada significa para él el sufrimiento de la esposa y las hermanas. Sin embargo, este acto de extrema crueldad le permite a Érica conseguir una nueva identidad, rompiendo así de manera definitiva el vínculo filial y logrando su liberación irreversible y total. Su hermana menor que no tiene el mismo coraje elige como escapatoria el suicidio.

Barreto da testimonio de la doble opresión de las mujeres. Dentro de sus propias familias el avasallamiento está sancionado por toda la sociedad. Este avasallamiento es mucho más brutal dentro del régimen dictatorial. Si bien la represión es igualmente atroz con hombres y mujeres, la situación de las mujeres víctimas de la dictadura no se visibiliza con la misma intensidad que cuando se trata de los hombres. La mujer es un mero objeto para ser usado y abusado por el dictador y sus secuaces. La escritora incorpora en sus novelas testimonios de personas involucradas en la militancia política, o testigos presenciales de los acontecimientos, generalmente poniéndoles nombres ficticios, pero también aporta fuentes recogidas en los documentos e investigaciones. Recurre a diferentes formas de narración: citas, memorias, cartas, diarios (ficticios o reales). En Los nombres que habito el relato gira alrededor de hechos poco estudiados hasta ahora - las historias de las niñas secuestradas para el uso de Stroessner y sus secuaces. Hasta hace poco en Paraguay era difícil dar con declaraciones sobre este horripilante proceder. Ahora, el silencio está roto, pero aún existe el miedo y la vergüenza que impiden el esclarecimiento de estos hechos espeluznantes. De momento, solo una mujer 
confesó ser una de las niñas del harén y dio un desgarrador testimonio (En línea 1). Otra habló sin revelar su identidad (En línea 2).

Algunos personajes, como la niña, fruto de la violación, víctima de abandono y abusos, o la esposa del torturador, solo encuentran refugio en la locura.

Chiquita las hace hablar. Es reveladora, intransigente, deja al descubierto la desintegración moral a la que sucumben los antiguos opositores y perseguidos cuando entran en los círculos del poder y lo comparten con sus antiguos verdugos.

En cuanto al lenguaje, su narrativa es dinámica. Rompe los moldes de escritura mezclando estilos y géneros, incluidos los 'menos nobles', como la novela rosa. A veces el lenguaje es refinado y poético, otras, es simple y vulgar. Escuchamos multitud de voces. El hilo narrativo de un amor juvenil, de repente, va intercalado con las crónicas de la Matanza de Caaguazu (como se conoce la represión a los campesinos en el año 1980) con todo el historial de torturas, muertes y desapariciones. Es polifónica. Admiramos esta polifonía de voces: de hombres, mujeres, víctimas y victimarios, en su sano juicio y sumidos en la locura, cercanos en el tiempo o de épocas pasadas. 'Voces confusas y confundidas. Voces que van desenredando historias de lastimaduras. Voces para no olvidar y voces olvidadas.' (Barreto, 2015).

\section{FINALIZANDO}

Chiquita Barreto es también cuentista y poetisa. Tanto en los cuentos, como en la poesía, detectamos la misma mirada femenina, valiente y sincera, que en sus novelas. Con su obra la temática paraguaya se inserta dentro de la creación femenina del post boom agregando las voces de mujeres paraguayas al coro polifónico de las escritoras latinoamericanas.

\section{REFERENCIAS BIBLIOGRÁFICAS}

Guardia, S. B. (s. f.) Literatura y Escritura femenina en América Latina. Disponible en http:// www.uesc.br/seminariomulher/anais/PDF/conferencias/SARA_ORIGINAL.pdf. [Consultado el 11 de marzo de 2019].

Makaran, G. (2014) Paraguay: el nacionalismo y sus mitos. México D.F.: Universidad Nacional Autónoma de México.

Martínez, A. (2002) Feminismo y literatura en Latinoamérica. Disponible en http://www. correodelsur.ch/Arte/literatura/literatura-y-feminismo.html. [Consultado el 17 de junio de 2019].

Méndez-Faith, T. (2009) Paraguay, novela y exilio. Asunción: Intercontinental.

Paz, O. (1950) El laberinto de la soledad. México D.F.: Fondo de Cultura Económica Mexicana.

Peiró Barco, J. V. y Rodriguez Alcalá, G. (1999) Narradoras paraguayas (antología). Disponible en http://www.cervantesvirtual.com/nd/ark:/59851/bmc668c0. [Consultado el 22 de mayo de 2019].

Zwierzeniec, M. (2015) La mujer en el mundo latinoamericano. Literatura, historia, sociedad el caso de México. Disponible en https://wszechnicapolska.edu.pl/.dokumenty/biblioteka/ publikacje-cyfrowe/zawierzeniec_lamujerenelmundolatinaomericano.pdf. [Consultado el 14 de junio de 2019]. 


\title{
RECURSOS DIGITALES
}

1) [En línea 1] Disponible en http://www.abc.com.py/edicion-impresa/politica/desgarradora-historia-de-una-esclava-sexual-en-los-tiempos-de-stroessner-1085515.html [Consultado el 12 de junio de 2019].

2) [En línea 2] Disponible en http://www.ultimahora.com/desgarrador-testimonio-esclavasexual-stroessner-y-sus-allegados-n2795315.html [Consultado el 2 de febrero de 2019].

\section{RECURSOS DE ANÁLISIS EMPÍRICO}

Barreto, Ch. (2010) Mujeres de cera (2a ed.). Asunción: Servilibro.

Barreto, Ch. (2011) La voz negada. Asunción: Servilibro.

Barreto, Ch. (2012) Al amparo del tiempo. Asunción: Servilibro.

Barreto, Ch. (2015) Los nombres que habito. Asunción: Fausto Ediciones.

Barreto, Ch. (2017) ¿Dónde van los gatos cuando llueve? Asunción: Servilibro.

\section{THE FEMALE UNIVERSE IN CHIQUITA BARRETO'S NOVELS}

\begin{abstract}
Paraguayan literature, a few exceptions aside, is very little known. This lack of knowledge is set in readers as much as in literary critics. Within Paraguay's literary corpus, feminine literature takes an important place. Chiquita Barreto, a Paraguayan writer, teacher and feminist, is the author of novels such as: Mujeres de cera (2010), La voz negada (2011), Al amparo del tiempo (2012), Los nombres que habito (2015), ¿Dónde van los gatos cuando llueve? (2012), and other stories and poem collections. In her writings Barreto always tackles women's issues. This article features an analysis of her novels, verifying their place within the main themes of female Latin American literature, especially those of the post-boom. This is a narrative space where codes are changed and several concepts are reinterpreted. Thus, the inclusion of the female body as free and independent, results in inhibition-free erotic literature. In another aspect, this body becomes a condemnation of gender violence. The legitimization and revaluation of marginalized domestic spaces, like the kitchen, produces what we call gastrotexts. The female participation in the fight against dictatorships is recovered for collective memory. Within the Paraguayan context, the subject of female militancy for the resistance against dictatorship has been marginalized. The rescue of female victims of the dictatorship has a fundamental importance in Barreto's narrative. Through the voice of her heroines, she tells us about family and political conflicts, blending intimate stories with the history of Paraguay, full of violence and pain.
\end{abstract}

Key words: Paraguayan literature, Chiquita Barreto, feminism, dictatorship

Krystyna Pisera (Máster en Estudios Ibéricos por la Universidad de Varsovia), actualmente ejerce docencia en la Universidad del Norte en Asunción, Paraguay. Sus intereses incluyen la literatura latinoamericana, traductología, estudios culturales. Correo electrónico: krystyna@tigo.com.py 